\title{
ALIMENTAÇÃO OU DIVERSÃO? A DIVERTIDA EXPRESSIVIDADE DAS MARCAS NO CONTEXTO CONTEMPORÂNEO DA PUBLICIDADE DE ALIMENTOS INFANTIS.
}

\author{
Food or Fun? The Funny Brands' expressions \\ in Contemporary Context of Child-Foods' Advertising.
}

\begin{abstract}
¿Alimentación ó Diversión? La divertida expresividad de las marca en el context contemporáneo de la publicidad de alimentos para niños.
\end{abstract}

Cinira Baader ${ }^{1}$

\begin{abstract}
Resumo
$\mathrm{O}$ artigo proposto é parte inicial de um projeto de pesquisa mais amplo que pretende concentrar-se no estudo da comunicação publicitária de alimentos infantis, considerando as expressividades de marcas manifestadas na tendência de consumo do eatertainment, por meio da análise semiótica peirceana dos principais elementos sígnicos presentes nesta comunicação e suas possibilidades de efeitos de sentido no comportamento alimentar das crianças na sociedade contemporânea. Um estudo que pretende contribuir para a produção científica no campo da comunicação, pois na medida em que visa contrastar a comunicação publicitária de produtos alimentícios dirigida às crianças com as questões referentes ao comportamento alimentar infantil na atualidade, busca entender se esta midiatização do consumo alimentar infantil alinha-se ou pode se alinhar às práticas desejáveis de consumo alimentar junto ao segmento em estudo. Assim talvez seja possível encontrar, no processo de regulação de sentidos dos discursos das marcas de alimentos, caminhos que se afinem com a regulação do setor alimentar e de suas comunicações para o público infantil.
\end{abstract}

Palavras-chave: publicidade, alimentos, público infantil, consumo, eatertainment.

\begin{abstract}
This paper is part of a broader research project which is focused in the study of child-foods' advertising, considering the different brands' expressions materialized in the current

\footnotetext{
${ }^{1}$ Bacharel em Comunicação Social (Publicidade e Propaganda) pela Universidade Regional de Blumenau (SC), com especialização em Gestão de Marketing pela mesma instituição. Mestranda do Programa de Pós-Graduação em Ciências da Comunicação da Escola de Comunicações e Artes da Universidade de São Paulo (ECA/USP). Email:c.baader@usp.br
} 
Alimentação ou diversão? A divertida expressividade das marcas no contexto contemporâneo da publicidade de alimentos infantis.

de Cinira Baader

consumption's trend of eatertainment, by semiotic analysis of the main signs present in this advertising and its possible senses' effects on children's eating habits in contemporary society. In this way, by highlighting the contrast between the actual context of child-foods' advertising and the contemporary questions related to children's eating habits, this study intends to identify, in the process of senses' regulation of food brands' discourses, possible ways that could be lined with the regulation of food market and its communications to the infant public.

Keywords: advertising, food, consumption, children, eatertainment.

\section{Resumen}

El artículo propuesto es la parte inicial de un proyecto de investigación más amplio que tiene como objetivo concentrarse en el estudio de la comunicación publicitaria de alimentos infantiles, teniendo en cuenta la tendencia de marcas en sus expresividades del consumo que se manifiestan com signos de entretenimiento, a través de un análisis semiótico de Peirce de los principales elementos de señalización presentar en esta comunicación y sus posibilidades de sentidos de los efectos sobre la conducta alimentaria de los niños en la sociedad contemporánea. Un estudio que tiene como objetivo contribuir a la producción científica en el campo de la comunicación, en la medida en que pretende contrastar la comunicación de la publicidad de alimentos dirigida a niños con problemas relacionados con los niños que comen hoy en día, trata de entender si esta mediatización de consumo de la alimentación infantil se alinea o puede ser deseable para alinear las prácticas de consumo de alimentos a lo largo del segmento en estudio. Así que tal vez usted puede encontrar, en la regulación de los significados de los discursos de las marcas de alimentos, los caminos que afinem con la regulación del sector de alimentos y sus comunicaciones a los niños.

Palabras-clave: publicidad, alimentos, niños, consumo, entretenimiento.

\section{EATERTAINMENT E HIPERCONSUMO ALIMENTAR INFANTIL}

No cenário das muitas e diversas mudanças vivenciadas hoje na dinâmica da sociedade hipermoderna (LIPOVETSKY, 2004 e 2007) vale destacar a questão dos novos hábitos alimentares, as novas experiências do universo da alimentação agora guiadas pelas leis do consumo emocional. 
Alimentação ou diversão? A divertida expressividade das marcas no contexto contemporâneo da publicidade de alimentos infantis.

de Cinira Baader

Com o ritmo acelerado típico da vida contemporânea, a velocidade e praticidade exigidas no dia-a-dia do cotidiano, a oferta crescente de produtos industrializados, e a busca constante por experiências de novidade, diversidade, alegria, prazer e bem-estar nos alimentos, os momentos de alimentação tendem a tornar-se cada vez mais individualizados, rápidos, práticos, e, de certo modo, menos artesanalmente estruturados - embora primando sempre por elementos de qualidade, criatividade, sensorialidade, prazer e diversão nos seus detalhes e rituais. Os momentos de alimentação muitas vezes já não representam mais espaços de encontro entre os membros da família e sim espaços de individualização, onde cada um pode experimentar os seus aromas e sabores de modo cada vez mais singular. Segundo Lipovetsky (2007) a alegria do comer e do beber antes era coletiva, materializada nas comilanças desmedidas que privilegiavam a quantidade e variedade à qualidade dos alimentos. Hoje experimentamos essa alegria de forma mais individualizada, materializada no prazer da degustação, nos elementos de criatividade, de novidade e de qualidade presentes nos momentos da alimentação. Assim,

[...] assiste-se, na França, a uma forte valorização do sabor dos alimentos, assim como a uma forte recuperação do referencial prazer. A felicidade alimentar não encontra mais sua plena expressão nos banquetes desmedidos, mas na sensualidade da degustação e na busca das qualidades gustativas. (LIPOVETSKY, 2007:235)

Todo esse novo contexto das práticas alimentares da sociedade hipermoderna, e também do mercado de produtos alimentícios em geral, pode ser em parte justificado pela lógica-moda. Neste sentido Lipovetsky (1989:159) observa: "A sociedade centrada na expansão das necessidades é, antes de tudo, aquela que reordena a produção e o consumo de massa sob a lei da obsolescência, da sedução, da diversificação, aquela que faz passar o econômico para a órbita da forma-moda." Daí toda a diversidade e novidade estabelecida hoje no mercado de alimentos (especialmente os alimentícios infantis) tendo em vista a constante necessidade renovada do hiperconsumidor da sociedade contemporânea, incluindo aqui as crianças. O hiperconsumidor quer o 'sempre mais', o 'sempre novo', o 'sempre melhor'. As crianças, hiperconsumidoras dinâmicas e intensas que são, querem tudo isso em dobro!

A lógica-moda acaba assim por provocar a transformação, ou melhor, a fusão dos conceitos de alimentação e diversão ou entretenimento. Nasce então, como trata Lipovetsky (2007), um novo conceito: o eatertainment (alimentação com diversão) - quando o 
Alimentação ou diversão? A divertida expressividade das marcas no contexto contemporâneo da publicidade de alimentos infantis.

de Cinira Baader

hiperconsumidor já não consegue mais conceber um momento de alimentação sem algum elemento de diversão. Uma nova necessidade que coloca em ação todo um mercado de produtos e serviços no setor alimentício, onde os ingredientes, aromas e sabores se misturam com todo um universo de fantasia, alegria e prazer (desde as prateleiras dos supermercados, as embalagens dos produtos industrializados, até os mais refinados restaurantes e cafés, passando, é claro, pelas incontáveis redes de fastfood). Vemos então,

... a alimentação conquistada, por sua vez, pela forma-moda, que transforma a refeição em entertainment, em divertimento total, com comidas inéditas, mise-en-scene criativa do prato, decoração design, música ao gosto do dia. Os anglo-saxões chamam essa tendência de eatertainment, como se a animação e o divertimento importassem tanto quanto o prazer da degustação dos pratos. (LIPOVETSKY, 2007:236)

Concentrando atenção ao conceito de eatertainment, é válido observar que, muito além de representar uma tendência consolidada no mercado de alimentos da sociedade contemporânea, o eatertainment representa um conceito que reflete a manifestação do fenômeno do hiperconsumo (alimentar) no âmbito do hipermodernismo. "Na sociedade de hiperconsumo, já não basta saborear pratos, a mesa deve ser a ocasião de uma 'viagem', de uma espécie de experiência sinestésica que satisfaz os seis sentidos, 'sendo o sexto sentido a emoção, a sensibilidade' (F Adriá)". (LIPOVETSKY, 2007:236)

Trata-se aqui de um fenômeno que não se revela unicamente junto ao consumidor infantil, mas que se manifesta com especial atenção a este sujeito que, no contexto do hiperconsumo, também se torna protagonista, manifestando seus desejos de consumo. O eatertainment se consolida como uma tendência de consumo para aqueles que buscam uma experiência diferenciada na alimentação. Se os adultos buscam o food design, a cozinha patchwork, cruzando alimentos do mundo, as crianças buscam comer se divertindo (LIPOVETSKY, 2007:235-236). E, talvez ainda mais do que no caso dos adultos, essa nova lógica da alimentação-diversão vem ao encontro das necessidades e desejos das crianças. São elas, pequenos hiperconsumidores, que parecem mais se divertir na combinação das novas cores, aromas e sabores do eatertainment.

Por assim representar um fenômeno de consumo tão marcante no comportamento alimentar da sociedade hipermoderna, o eatertainment passa a se refletir também como tendência de base estratégica no mercado de alimentos. Conforme Galindo (2008) a indústria de produtos alimentícios (especialmente os alimentícios infantis) passa a basear suas estratégias de 
Alimentação ou diversão? A divertida expressividade das marcas no contexto contemporâneo da publicidade de alimentos infantis.

de Cinira Baader

comunicação e marketing na constante combinação alimentação-diversão, a fim de atrair e falar diretamente com o seu público-alvo (as crianças). Assim, as ações de mercado baseadas no eatertainment vêm ganhando crescente espaço na indústria de produtos alimentícios infantis nos últimos anos, materializadas especialmente no campo da publicidade. "Se a publicidade por si só já influencia o público infantil, a possibilidade de proporcionar entretenimento à experiência do consumo é capaz de potencializá-la. A estratégia tem crescido muito, principalmente na indústria de alimentos." (GALINDO, 2008:9).

A partir desse cenário de diversão e encantamento a indústria de alimentos infantis passa a oferecer às crianças uma gama cada vez mais repleta de produtos, em toda a sua multiplicidade de cores, aromas, sabores, embalagens, brindes e personagens, trazendo para os seus pequenos consumidores um universo fantástico de alimentação, diversão, comunicação e interatividade. Os principais recursos explorados nas ações de comunicação e marketing de alimentos infantis, a partir da tendência do eatertainment, ganham forma especialmente nas estratégias da utilização de brindes e personagens vinculados às marcas, produtos ou às peças publicitárias. A utilização dessas estratégias é sinalizada por diversos autores, como Kapferer, Montigneaux, Linn, além de Lewin (1992) e Galindo (2008) - considerando tanto avaliações a respeito do potencial mercadológico dos brindes e personagens, o encantamento das crianças com tais recursos lúdicos, quanto observações com relação às suas eventuais possibilidades de efeitos nocivos junto ao público infantil.

No contexto da alimentação-diversão vale observar que uma das propostas modernas na indústria de alimentícios que mais se destaca junto ao público infantil (e que muitas vezes se utiliza da combinação de brindes e personagens nos seus produtos) é representada pelo segmento de fastfood: lanches de todos os tipos, cores, sabores, com brindes e personagens que fazem a alegria dos pequenos. Fischler (1998:860) destaca o tema, mencionando como exemplo ilustrativo o contexto do sucesso mundial da marca McDonald's. Segundo o autor, a experiência do lanche fastfood torna-se uma preferência universal entre as crianças, mesmo para aquelas ainda muito pequenas, pela sensação de prazer, liberdade e autonomia que tal momento lhes proporciona, quase que como numa experiência de lazer (uma experiência de eatertainment).

Na contrapartida desse cenário, no entanto, e aqui marcando bem o caráter paradoxal do universo do hiperconsumo, é possível observar que em meio a essa divertida e diversa gama de produtos alimentícios oferecidos às crianças hoje no mercado, há também a presença de muitos 
Alimentação ou diversão? A divertida expressividade das marcas no contexto contemporâneo da publicidade de alimentos infantis.

de Cinira Baader

produtos hipercalóricos ou de baixo valor nutricional, o que na realidade acaba por denotar maior atenção à beleza e atratividade do que à qualidade dos alimentícios infantis (LEWIN, 1992:506). E o que pode ser ainda mais preocupante é o fato de que, além de tais produtos constituírem alimentos hipercalóricos ou de baixo valor nutricional, muitos deles contém elementos em sua composição que podem ser prejudiciais à saúde e desenvolvimento infantil. Torna-se assim cada vez mais presente a preocupação com a qualidade dos alimentos consumidos pelas crianças no seu cotidiano e com os efeitos dessa alimentação nos índices de saúde infantil.

Por esta razão muitos setores da sociedade têm levado ao debate uma série de questões sobre as práticas modernas do mercado de produtos alimentícios infantis. Problemas que hoje afetam em níveis consideráveis a saúde das crianças (como a obesidade infantil, o consumo em excesso de açúcares e gorduras, os distúrbios alimentares) vêm sendo apontados como consequiências prováveis de uma alimentação de má qualidade, baseada em alimentos hipercalóricos e de baixo valor nutricional, oferecida com freqüência às crianças na atualidade por meio das ações da indústria, do varejo e da publicidade de alimentos infantis.

A partir desse contexto das estratégias atuais da indústria e da publicidade de alimentos infantis a diversão torna-se o elemento, o conteúdo principal nas peças e campanhas publicitárias de produtos alimentícios para crianças. No entanto, percebe-se que a atratividade deste conteúdo de diversão pode acabar se sobrepondo à necessidade de informação referente aos valores nutricionais dos produtos, instruções para moderação no consumo, possíveis efeitos nocivos para a saúde infantil. Muitas das referências que as crianças têm sobre os alimentos que elas consomem acabam passando antes pelas possibilidades de diversão do que pelas necessidades de nutrição, uma vez que “[...] o que é posto em destaque pela propaganda não é o valor nutricional dos alimentos, mas a capacidade de entreter, de tornar o cotidiano da criança mais divertido." (GALINDO, 2008:10). O que também é sinalizado por Lewin (1992:511).

Assim, vale observar que, do mesmo modo com que a partir de agora passa a haver maior preocupação com a qualidade, a composição dos alimentícios dirigidos às crianças (e seus possíveis efeitos na saúde infantil), também esta preocupação passa a se fazer presente em relação à composição da comunicação publicitária de tais produtos (e seus possíveis efeitos no comportamento alimentar das crianças). O que se coloca em pauta é a avaliação do eventual papel da publicidade de produtos alimentícios dentre os fatores de influência no comportamento alimentar das crianças na atualidade. Nesse contexto, eis então a proposta do estudo que aqui se 
Alimentação ou diversão? A divertida expressividade das marcas no contexto contemporâneo da publicidade de alimentos infantis.

de Cinira Baader

apresenta, atendendo à necessidade de se dedicar atenção especial a tal problemática, com foco específico no campo da midiatização publicitária de alimentos infantis e suas possibilidades de efeitos de sentido no comportamento alimentar das crianças nos tempos da hipermodernidade.

\section{OS SIGNOS DA ALIMENTAÇÃO-DIVERSÃO E SUAS POSSIBILIDADES DE SENTIDOS NA PUBLICIDADE DE ALIMENTOS INFANTIS}

Partindo do referencial teórico apresentado, entende-se que neste ponto torna-se essencial a atenção a uma análise mais aprofundada das composições e mediações sígnicas presentes na produção de peças publicitárias de alimentos infantis, bem como, a avaliação das suas possibilidades de efeitos de sentido junto ao comportamento alimentar das crianças em seus cotidianos.

Nesse sentido, a pesquisa que se propõe pretende explorar e avaliar pontos específicos e relevantes para o aprofundamento e sofisticação do tema em estudo. Ao proceder à identificação de peças ou campanhas publicitárias televisivas no segmento de produtos alimentícios dirigidos ao público infantil baseadas na tendência de consumo do eatertainment, e tendo-se em conta a metodologia proposta e, sobretudo, aquilo que se pretende empreender para análise das mensagens publicitárias estudadas, pretende-se observar, a partir das dimensões triádicas do signo em Peirce, como propõe Santaella (2002), a seguinte linha de leitura: 1) a relação com o signo em si, que se refere ao que o signo marca comunica na publicidade; 2) a relação do signo com o objeto que representa, ou seja, como os alimentos são representados, como se dá a relação alimentação-diversão, e como se sugere a prática de consumo alimentar para a criança; 3) o signo em relação ao interpretante, isto é, o que o signo publicitário deixa como sentido potencial, que repercussões possíveis pode ter sobre o consumo alimentar infantil.

Nesta fase inicial do estudo, no entanto, como que num primeiro ensaio da pesquisa a que o projeto como um todo se propõe, esta abordagem se deu a partir da análise de uma única peça publicitária televisiva de produto alimentício infantil, veiculada na programação infantil atual de tevê aberta, uma vez que se trata aqui de um estudo qualitativo e que pretende ser devidamente ampliado e aprofundado nos devidos tempos do seu percurso. Mas uma análise que, embora em sua fase inicial, já demonstrou em si potencial para apontar amostras significativas de algumas 
Alimentação ou diversão? A divertida expressividade das marcas no contexto contemporâneo da publicidade de alimentos infantis.

de Cinira Baader

das possibilidades de mediações sígnicas e efeitos de sentidos presentes na midiatização publicitária de alimentos infantis na atualidade.

Mas antes de partirmos para o relato da análise da peça publicitária selecionada, seria interessante uma breve exposição para justificativa da utilização da semiótica peirceana como base metodológica para o estudo proposto.

\subsection{A Semiótica Peirceana: Base Teórico-Metodológica para a Análise}

A opção pela utilização da semiótica peirceana como base metodológica para o estudo proposto se dá pela íntima relação que esta abordagem teórica estabelece com o estudo dos signos, linguagens, percepções e produção de significados. Natureza que torna a semiótica uma teoria também muito íntima do campo de estudo da comunicação, no compartilhamento da sensibilidade aos processos de linguagem, percepção, representação e universos simbólicos presentes nas esferas da produção e recepção idealizada das mensagens. (SANTAELLA, 2002:59).

Num momento onde o mundo passa por tantas mudanças e transformações a comunicação se coloca como propulsora e também como reflexo desse acelerado processo de evolução. Evolução que se dá essencialmente no universo dos signos, os quais produzem sempre mais e novos signos, linguagens, interpretações, significados. Crescem os signos, cresce também a necessidade de se aprender a lê-los, interpretá-los, comunicá-los. Os signos se multiplicam e as formas de comunicação dos mesmos também. Isso se faz presente especialmente no universo da comunicação com o público infantil e juvenil, onde há ansiedade constante pela busca de novidade, inovação. E nesse contexto, a semiótica peirceana se mostra como uma das poucas abordagens teóricas capazes de acompanhar, no estudo dos signos, essa evolução do novo e do efêmero. (SANTAELLA,2002:xiv)

A comunicação publicitária representa hoje um dos mais atuantes e eficientes meios de criação, produção e propagação de signos na vida social, independentemente das possíveis funções ou finalidades de seus usos. A semiótica vem assim trazer todo o conhecimento e técnica necessários para uma melhor e mais profunda compreensão desse tão vasto universo dos signos e suas traduções no mundo contemporâneo. "Diante disso é que as relações entre marketing, publicidade e semiótica estão a cada dia mais evidentes tendo em conta a complexificação da 
Alimentação ou diversão? A divertida expressividade das marcas no contexto contemporâneo da publicidade de alimentos infantis.

de Cinira Baader

nossa sociedade que cada vez mais consome símbolos construídos em grande parte pela publicidade no mundo capitalista." (PEREZ, 2004:142).

Após esta breve exposição a respeito das possibilidades de interação e complementaridade entre os estudos da semiótica e da comunicação, partimos então para o relato da análise proposta neste estudo.

\section{2. $\quad$ Análise da Peça Publicitária McLanche Feliz (Smurfs) / McDonald's}

A peça selecionada para análise é parte de uma das campanhas do McDonald's para divulgação promocional do produto McLanche Feliz, veiculada no mês de julho de 2011, em campanha televisiva, na programação infantil de tevê aberta e fechada. A peça é alusiva ao lançamento da linha de brindes promocionais do McLanche Feliz com motivos dos personagens The Smurfs - personagens do filme The Smurfs (Sony Pictures Animations \& Columbia Pictures) estreado nos cinemas brasileiros no início do mês de agosto de 2011. (visualização da peça disponível em: http://www.youtube.com/watch?v=ISxE7DJvq9w)

A escolha da peça se deu tendo em vista os seguintes critérios: 1) excelência da marca McDonald's na utilização de estratégias baseadas na tendência do eatertainment em todas as suas campanhas e plataformas de comunicação com o público infantil; 2) campanha promocional envolvendo a combinação de brindes e personagens, o que representa uma das principais modalidades estratégicas baseadas no conceito de eatertainment; 3) peça publicitária dirigida especialmente ao público infantil, o que se enquadra especificamente no objeto deste estudo; 4) visibilidade dos personagens figurados como motivos temáticos dos brindes da promoção: personagens presentes na mídia e no mercado de produtos em geral por conta do lançamento e estréia do filme; 5) veiculação atual e recente da campanha: mês de julho de 2011, mesma época dos preparativos para a estréia do filme The Smurfs nos cinemas.

Na seqüência, após a breve descrição e contextualização da peça e a enunciação da justificativa de seleção da mesma para a pesquisa, partimos então para a análise sígnica do anúncio sob o enfoque metodológico da semiótica peirceana, utilizando como base Santaella (2002).

\subsubsection{Os Signos da Alimentação-Diversão em sua Essência}


Alimentação ou diversão? A divertida expressividade das marcas no contexto contemporâneo da publicidade de alimentos infantis.

Conforme Santaella (2002) todos os processos comunicativos, tomados como signos, são em si constituídos de três faces: a significação, a referência e a interpretação. $\mathrm{Na}$ face da significação, a primeira face constitutiva dos processos de comunicação,

... a análise semiótica nos permite explorar o interior das mensagens em seus três aspectos. $O$ primeiro deles diz respeito às qualidades e sensorialidade de suas propriedades internas (...). $O$ segundo aspecto diz respeito à mensagem na sua particularidade, no seu aqui e agora em um determinado contexto. O terceiro aspecto se refere àquilo que a mensagem tem de geral, convencional, cultural. (SANTAELLA, 2002:60)

Nesse sentido, a primeira dimensão da nossa análise se dará então na face da significação. Tomando como signo a peça publicitária McLanche Feliz (Smurfs), é possível observar que, em seu aspecto qualitativo, o primeiro aspecto da face da significação, a peça evoca sensações de alegria, diversão, entretenimento, graça; momentos de sonho, de fantasia, onde o real se mistura com o imaginário; uma encantada combinação de música, personagens, crianças, sorrisos, coisas gostosas; tudo colorido, divertido, num ambiente de muita melodia, alegria e prazer. Signos do encantamento, da diversão.

Em seu aspecto de singularidade, o segundo aspecto da face da significação, é possível observar que se trata de uma peça publicitária televisiva da marca McDonald's, alusiva à campanha do McLanche Feliz, com brinquedos colecionáveis, tematizados com personagens do filme The Smurfs. Peça de conteúdo lúdico na qual o texto e as imagens falam dos personagens e da novidade dos brindes oferecidos pelo McDonald's durante o mês da promoção. Trata-se de uma campanha que se encontra em veiculação na programação atual de televisão e que está ligada ao evento de estréia do filme The Smurfs nos cinemas.

Já no seu aspecto de generalidade, o terceiro aspecto da face da significação, pode-se observar que se trata de um comercial de televisão dirigido ao público infantil, concebido nos padrões comuns de comunicação com este público (utilização de música, personagens, humor, diversão, etc.). Observa-se também que se trata de mais uma das campanhas do McDonald's para promoção do McLanche Feliz, com o lançamento de novos personagens e brindes (seguindo o padrão seqüencial das demais campanhas da marca para este produto). E pode-se observar ainda que se caracteriza como uma peça publicitária baseada no conceito de eatertainment em sua 
Alimentação ou diversão? A divertida expressividade das marcas no contexto contemporâneo da publicidade de alimentos infantis.

de Cinira Baader

composição, misturando elementos do universo da alimentação e da diversão para falar diretamente às crianças no segmento de alimentícios infantis.

Trazendo esta dimensão da análise para o tema em estudo, no contexto da tendência e do conceito de eatertainment, podemos dizer então que, na composição, no conteúdo da peça analisada tomada como signo temos aspectos singulares do mercado da alimentação infantil (a marca McDonald's e o produto McLanche Feliz) envolvidos por aspectos qualitativos do universo da diversão (os brindes da promoção e o mundo encantado e divertido dos personagens The Smurfs), para assim se colocarem nos padrões dos aspectos genéricos da publicidade infantil de alimentos da atualidade, onde a combinação dos elementos alimentação e diversão se faz cada vez mais presente, mais essencial.

\subsubsection{Os Signos da Alimentação-Diversão em Sua Aplicação}

Prosseguindo com base em Santaella, passamos agora para a face da referência, a segunda face constitutiva dos processos comunicativos. De acordo com a autora, nesta face

... a análise semiótica nos permite compreender aquilo que as mensagens indicam, aquilo a que se referem ou se aplicam. Também nesta face encontramos três aspectos: o primeiro aspecto deriva do poder meramente sugestivo tanto sensorial como metafórico das mensagens. $O$ segundo aspecto deriva do poder denotativo das mensagens, sua capacidade para indicar algo que está fora delas. O terceiro aspecto deriva da capacidade das mensagens para representar idéias abstratas e convencionais, culturalmente compartilhadas. (SANTAELLA, 2002:60)

Partindo então para a segunda dimensão da nossa análise, onde o foco se dá na face da referência, e continuando a tomar como signo a peça publicitária McLanche Feliz (Smurfs), é possível observar que, em seu primeiro aspecto da face da referência, no nível do poder de sugestão, a peça sugere muita diversão e alegria para as crianças, como que convidando-as a tomar parte num universo mágico de fantasias, cheio de surpresas e brincadeiras. Um universo que pode ser tão encantado e divertido quanto o mundo dos personagens dos filmes no cinema e na televisão.

Num segundo aspecto da face da referência, no nível do poder de denotação, observa-se que a peça indica que todo esse universo de fantasias e diversão sugerido para as crianças está esperando por elas nas lojas do McDonald's, especialmente neste mês, com a presença dos personagens The Smurfs nos brindes do McLanche Feliz. Interessante observar aqui também o 
Alimentação ou diversão? A divertida expressividade das marcas no contexto contemporâneo da publicidade de alimentos infantis.

de Cinira Baader

fato de que, embora o produto McLanche Feliz seja em si um alimentício, a peça pouco se refere ao produto e seus atributos. Indica a presença do produto alimentício apenas através de algumas imagens (cenas rápidas dos personagens ajudando a preparar os lanches; as crianças comendo nugets; ou closes das embalagens do McLanche Feliz). No texto nada é referenciado, ao menos não diretamente. A principal referência da peça (texto, imagens, trilha sonora) se concentra nos personagens, no universo encantado de The Smurfs, no mundo divertido da marca McDonald's.

Em seu terceiro e último aspecto da face da referência, agora no nível do poder da representação abstrata, vale observar que a peça analisada representa, faz referência especial à idéia de diversão, até mesmo sobrepondo-se à idéia de alimentação. No plano das idéias observase que, mesmo nos momentos em que há referência à idéia de alimentação (os produtos do McLanche Feliz), esta representação se dá caracterizada pela idéia de diversão (os brinquedos com os personagens The Smurfs). Assim, pode-se dizer então que a peça publicitária analisada é, em si, capaz de representar a materialização do conceito de eatertainment. A peça reflete em si as práticas culturais contemporâneas da alimentação (especialmente a alimentação infantil) onde os rituais tendem a ser sempre envolvidos de emoção, fantasia, prazer e muita diversão.

Buscando agora um paralelo entre esta dimensão da análise e o tema em estudo, no contexto da tendência e do conceito de eatertainment, é possível afirmar que, à primeira vista, temos na peça analisada a manifestação de um poder de denotação que destaca elementos do mercado de alimentícios infantis (a marca McDonald's e o produto McLanche Feliz), com base em um poder de sugestão que demanda um universo de alegria e diversão (os personagens The Smurfs e os mini-brinquedos colecionáveis oferecidos pela marca), para assim dar forma ao seu poder de representação, materializado especialmente na idéia de alegria, de prazer, de entretenimento, de diversão, sobrepondo-se à idéia de alimentação (quando os personagens ganham mais destaque na peça do que os produtos alimentícios em si), caracterizando o que se coloca na sociedade contemporânea como principal tendência no consumo e na comunicação publicitária de alimentícios infantis.

\subsubsection{Os Signos da Alimentação-Diversão em seu Potencial}


Alimentação ou diversão? A divertida expressividade das marcas no contexto contemporâneo da publicidade de alimentos infantis.

de Cinira Baader

Novamente tomando Santaella como base, é possível finalizar nossa análise considerando a terceira das faces constitutivas dos processos comunicativos: a face da interpretação. Conforme a autora, nesta face

... a análise semiótica nos habilita a examinar os efeitos que as mensagens podem despertar no receptor. Esses efeitos são de três tipos: os primeiros são os efeitos emocionais, quando o receptor é tomado por um sentimento mais ou menos definido; os segundos são os efeitos reativos, quando o receptor é levado a agir em função da mensagem recebida; os terceiros são mentais, quando a mensagem leva o receptor a refletir. (SANTAELLA, 2002:60)

Assim, tomando-se ainda como signo a peça publicitária McLanche Feliz (Smurfs), e concentrando atenção ao primeiro aspecto da face da interpretação, podemos destacar que, no nível dos efeitos emocionais, a peça pode despertar nas crianças (principais receptores / hiperconsumidores), mas também nos pais (consumidores que se alegram com a alegria de consumo dos filhos), alguns sentimentos meio concretos meio abstratos como: alegria (ao serem tomados pelo universo de diversão proposto pela marca); encantamento (ao serem tocados pelo imaginário dos personagens); desejo de experimentar, de estar lá (ao entrarem em contato com o universo da marca, dos produtos, dos personagens). Esses efeitos emocionais de sentimentos que podem ser despertados nos receptores (especialmente no caso das crianças) são viabilizados principalmente por meio de elementos como a trilha sonora (tema musical dos personagens no filme estreado nos cinemas), as imagens dos personagens em ação (as adoráveis criaturinhas azuis contracenando com as crianças e com os funcionários da loja), e todo o conceito que caracteriza o ambiente da marca McDonald's (que certamente já tem seu espaço na cabeça e no coração das crianças). Interessante observar também que, no caso específico destes personagens (The Smurfs) que representam uma novidade para as crianças da contemporaneidade, a peça pode despertar nos adultos um sentimento de viagem encantada ao passado, boas recordações da infância (numa tendência de consumo regressivo), já que na verdade os personagens são antigos e estão agora retornando às telas da tevê e do cinema após um longo período de retirada.

Concentrando atenção agora ao segundo aspecto da face da interpretação, no nível dos efeitos reativos (ou energéticos), podemos considerar que a peça é bastante convidativa, especialmente para as crianças, no sentido de tentar levá-las até as lojas, despertando-lhes o desejo, o impulso de experimentar toda essa diversão, de comer os lanches, de brincar com os personagens. A peça pode despertar esses efeitos de energia e ação nas crianças principalmente 
Alimentação ou diversão? A divertida expressividade das marcas no contexto contemporâneo da publicidade de alimentos infantis.

de Cinira Baader

por meio da oferta dos brindes (que no caso do McLanche Feliz são sempre brinquedos colecionáveis) e da participação dos personagens (que já ganham destaque junto às crianças em outras mídias por conta dos preparativos para a estréia do filme nos cinemas). Neste sentido, esta promoção publicitária do McLanche Feliz pode envolver as crianças numa seqüência de visitas às lojas que certamente não se limitaria a uma única experiência. Uma possibilidade de efeito energético continuado junto às crianças (ora para alegria dos pais, ao contemplarem a alegria dos filhos; ora para seu total descontentamento, ao não saberem o que fazer diante de tantos pedidos insistentes dos pequenos consumidores).

E com a atenção voltada ao terceiro e último aspecto da face da interpretação, é possível observar que, no nível dos efeitos mentais (ou lógicos), a peça tem a intenção primeira de dar ao conhecimento das crianças sobre a nova promoção da marca para o McLanche Feliz, e assim o faz, mostrando-lhes os novos personagens e convidando-as a participar deste universo de diversão e fantasia que espera por elas nas lojas do McDonald's. Além disso, a peça também pode despertar ou intensificar a admiração e o carinho das crianças pela marca McDonald's, uma vez que, a cada nova promoção publicitária, as crianças tomam conhecimento de novos brindes e personagens que lhes são ofertados nas lojas, reafirmando a cada vez o conceito de que se trata de uma marca que sabe do que as crianças gostam, que está sempre ligada aos seus personagens favoritos, e que sempre vai lhes oferecer algo divertido, sempre uma nova surpresa. E no caso específico desta promoção com os personagens The Smurfs, a peça pode ainda criar um efeito lógico de sinergia entre a promoção em si e o evento de estréia do filme, onde crianças e adultos podem misturar, combinar os conhecimentos e experiências vivenciados no cinema (ao assistirem ao filme) com os conhecimentos e experiências vivenciados nas lojas (no consumo dos lanches e colecionamento dos brinquedos com o tema dos personagens). Nota-se, no entanto, pouca intenção de efeito interpretativo, nesta peça publicitária, com relação aos produtos em si, na temática da alimentação (os lanches e seus atributos para o consumo infantil). Ao menos isso não se mostra de forma direta, no nível das possibilidades de efeitos lógicos. A intenção se volta quase que exclusivamente para efeitos de interpretação no universo do lúdico, do entretenimento (os personagens, as surpresas, os brindes, a diversão).

Finalmente, na tentativa de se ligar esta última dimensão da análise com o tema central do estudo, baseado no contexto da tendência e do conceito de eatertainment, vale observar que a peça analisada traz em si diferentes possibilidades de efeitos interpretativos, mas todos ligados 
Alimentação ou diversão? A divertida expressividade das marcas no contexto contemporâneo da publicidade de alimentos infantis.

de Cinira Baader

entre si. Primeiramente, nas suas possibilidades de efeitos energéticos, a peça pretende levar as crianças à ação, à diversão, ao consumo. Mas isso, ela somente pode fazê-lo se com base nas suas possibilidades de efeitos emocionais, onde as crianças podem ser ao mesmo tempo tomadas pela emoção, o sentimento de paixão (pela marca, pelos produtos, pelos personagens), o desejo da alegria, do prazer, da diversão. Isso para se chegar enfim às suas possibilidades de efeitos lógicos que, no caso desta peça, por tratar-se de comunicação dirigida às crianças, esses efeitos ficam mais concentrados no nível do conhecimento do que da reflexão - possibilitar às crianças tomarem conhecimento dos personagens, da promoção, fazê-las reconhecer a marca McDonald's como portadora de uma nova oportunidade de entretenimento, de surpresa, de diversão, muito além dos produtos oferecidos para alimentação. Mais uma vez, se faz assim mostrar na comunicação publicitária de alimentos infantis a materialização do conceito alimentaçãodiversão, como que num reflexo do fenômeno do eatertainment, tão presente no consumo alimentar das crianças do mundo contemporâneo.

\section{ALGUMAS CONSIDERAÇÕES}

A partir desta abordagem inicial da pesquisa (uma análise que embora em sua fase inicial já demonstrou em si potencial para apontar amostras significativas de algumas das possibilidades de mediações sígnicas e efeitos de sentido presentes na midiatização publicitária de alimentos infantis na atualidade), se fez possível explorar e identificar uma série de elementos interessantes para o estudo proposto.

A análise aqui empreendida, realizada por meio da leitura semiótica peirceana da peça McLanche Feliz (Smurfs) / McDonald's, revelou elementos bastante significativos para uma compreensão mais aprofundada (embora ainda inicial) das mediações sígnicas e possibilidades de efeitos de sentido que se colocam presentes na comunicação publicitária de alimentos infantis em tempos atuais, no contexto da combinação alimentação-diversão, que reflete o fenômeno do eatertainment como manifestação do hiperconsumo alimentar infantil na sociedade hipermoderna.

Nesse sentido, após a apresentação do referencial teórico e do relato da análise realizada, nosso estudo deixa uma proposta de reflexão: a partir do momento em que a publicidade de alimentos infantis, refletindo uma tendência já consolidada no contexto do consumo alimentar da 
Alimentação ou diversão? A divertida expressividade das marcas no contexto contemporâneo da publicidade de alimentos infantis.

sociedade hipermoderna (o eatertainment), passa a se utilizar de elementos do universo da diversão para combiná-los a elementos do universo da alimentação na composição dos seus apelos de comunicação para o público infantil, e assim o faz, mas indo além, recriando a combinação alimentação-diversão numa ótica quase que exclusiva da diversão, ela (a publicidade) não poderia estar, além de simplesmente refletindo o fenômeno do eatertainment como tendência, também potencializando tal fenômeno, como que no sentido da sua possível sustentação, legitimação e maximização? E, nesta ótica, não se poderia passar a pensar a publicidade de alimentos infantis também como um dos atores de influência e responsabilidade no processo atual da mudança de comportamentos e hábitos alimentares das crianças nas sociedades da hipermodernidade?

\section{REFERÊNCIAS BIBLIOGRÁFICAS}

FISCHLER, Claude. A McDonaldização dos costumes. In FLANDRIN, Jean-Louis; MONTANARI, Massimo. História da alimentação. São Paulo : Estação Liberdade, 1998. $885 p$, il.

GALINDO, Daniel. Eatertainment: a divertida publicidade que alimenta o público infantil. Disponível em: www.alaic.net/alaic30/ponencias/cartas/.../GT5_3GALINDO.pdf

LEWIN, Zaida Grinberg. A criança, os comerciais de televisão e a cultura alimentar: uma análise crítica. In: Educação E sociedade, v. 13, n. 43, p. 504 523, dez. 1992.

LIPOVETSKY, Gilles. A felicidade paradoxal: ensaio sobre a sociedade de hiperconsumo. São Paulo (SP):Companhia das Letras, 2007.402 p.

LIPOVETSKY, Gilles. O império do efêmero: a moda e seu destino nas sociedades modernas. São Paulo : Cia das Letras, 1989, c1987. 294p.

LIPOVETSKY, Gilles. Os tempos hipermodernos. São Paulo: Barcarolla. 2004.129

PEREZ, Clotilde. Signos da marca: expressividade e sensorialidade. São Paulo:Thomson, 2004.174p,il.

SANTAELlA, Lucia. Semiótica aplicada. São Paulo : Pioneira Thomson Learning, 2002. xvii, $186 \mathrm{p}$, il.

Artigo recebido: $15 / 05 / 2011$ 
Alimentação ou diversão? A divertida expressividade das marcas no contexto contemporâneo da publicidade de alimentos infantis.

de Cinira Baader

Artigo aprovado: 10/06/2011 